\title{
Kewirausahaan Sosial dan Penciptaan Nilai Bersama: Sebuah Kajian terhadap CSR Sido Muncul untuk Program Desa Rempah dan Buah
}

\author{
Hani Sirine*, Roos Kities Andadari, Lieli Suharti \\ Program Studi Manajemen, Fakultas Ekonomika dan Bisnis, Universitas Kristen Satya \\ Wacana, Salatiga, Indonesia \\ *hani.sirine@uksw.edu
}

\begin{abstract}
CSR with a shared value creation approach is characterized by the concept of social entrepreneurship, so as to produce a new business model from the social changes that occur. The purposes of this study are to determine the process of developing social entrepreneurship in the Spice and Fruit Village CSR Program and to identify the creation of shared values resulting from Sido Muncul CSR program. The research method used is qualitative in which the validity of the data is tested by the triangulation method. Data collection was carried out through interviews and observations with Sido Muncul and fostered residents for the Spice and Fruit Village Program in Bergas Kidul and Diwak Villages. The results of this study indicate that the process of developing social entrepreneurship in CSR programs is carried out through several stages, including identification of social problems, allocation of resources, collaboration and partnerships, adaptation of products and processes, and social innovation. The creation of shared values resulting from the CSR program is organizational performance and social performance. Organizational performance can be seen through management support, employee commitment, company reputation, and organizational finance. Social performance can be seen through the role of social entrepreneurship, harmonious relationships between shareholders and stakeholders, social innovation, and community independence. Organizational performance has a reciprocal relationship with social performance, which can produce sustainable growth.
\end{abstract}

Keywords: CSR, Social Entrepreneurship, Shared Value Creation

\section{PENDAHULUAN}

Perusahaan sebagai suatu sistem ekonomi, mengadopsi berbagai sumber daya yang terintegrasi baik dalam proses produksi serta distribusi barang dan jasa sehingga tercipta keseimbangan rantai nilai. Selain mempertimbangkan keuntungan, perusahaan juga dapat memberikan kontribusi untuk mengatasi persoalan sosial dan keberlanjutan organisasi di tengah masyarakat. Suatu konsep pengembangan yang berkelanjutan untuk pemangku kepentingan adalah Tanggung Jawab Sosial Perusahaan (CSR). Menurut Lantos (2001), korporasi abad ke-21 telah menyadari bahwa kewajiban perusahaan terhadap masyarakat dalam hal tanggung jawab sosial perusahaan ada empat: yaitu ekonomi, etika, altruistik, dan strategis. Perusahaan harus menulis ulang model 
bisnisnya untuk mengakomodasi pemenuhan kewajiban ini.

Konsep Corporate Social Responsibility telah berevolusi, yang tadinya bersifat filantropis, namun saat ini menciptakan pendekatan penciptaan nilai bersama yang diusulkan oleh Porter dan Kramer (2006). Menurut Falck dan Heblich (2007), perusahaan yang dianggap bertanggung jawab sosial oleh para pemangku kepentingan akan bertahan dan makmur. Perusahaan akan diawasi oleh pemerintah, LSM, dan media, untuk mempertanggungjawabkan konsekuensi sosial dari kegiatan operasionalnya (Porter \& Kramer, 2006), dan untuk menilai kinerja lingkungannya (Idowu, Louche, \& Filho, 2013).

Saatci dan Urper (2013) menyatakan prinsip penciptaan nilai bersama ditandai dengan konsep kewirausahaan sosial. Kewirausahaan sosial adalah proses yang bertujuan untuk mengkatalisasi perubahan sosial (Mair \& Mart1, 2006). Untuk itu tujuan kewirausahaan ini adalah meringankan penderitaan kelompok sasaran (Martin \& Osberg, 2007) dengan cara mendistribusikan nilai sosial yang baru (Perrini \& Vurro, 2006). Perusahaan tetap dapat mencari laba namun dengan komitmen yang kuat untuk bertanggung jawab secara sosial kepada para pengampu kepentingan (Saatci \& Urper, 2013).

Penciptaan nilai bersama adalah titik kunci dalam pengembangan model kewirausahaan sosial, yang tidak hanya melibatkan kepentingan para stakeholder namun juga kewirausahaan yang muncul dari peluang sosial (Marquez et al., 2010). Hal ini akan melibatkan interaksi dengan organisasi yang berbeda, yang diarahkan untuk menghasilkan barang dan jasa di sepanjang rantai nilai. Perusahaan dapat mengatasi masalah sosial dengan memberikan akses modal, pasar, dan teknologi untuk menciptakan nilai bersama yang berkelanjutan (Lodge \& Wilson, 2006).

López, Garcia, dan Rodriguez (2007) menyatakan bahwa perusahaan yang melakukan praktik CSR dipercaya dapat meningkatkan keuntungan perusahaan dalam jangka panjang dari adanya investasi sosial. Nilai-nilai perusahaan yang terdapat dalam aktifitas CSR penting untuk memajukan kinerja organisasi sehingga perusahaan dapat dipercaya, sebagai agen moral, dan memberi solusi inovatif untuk masalah-masalah sosial (Vachani \& Smith, 2008). Jika perusahaan tidak dapat mengimbangi keuntungan stakeholder yang hilang, maka kemungkinan perusahaan dapat kehilangan legitimasi sosial karena pemangku kepentingan kehilangan kepercayaan pada kinerja perusahaan (Wood, 2014).

Sido Muncul sebagai perusahaan jamu dan farmasi yang berdiri sejak tahun 1951, memiliki market share tertinggi dan reputasi yang baik sebagai industri jamu terbesar di Indonesia. Perusahaan yang telah go public sejak tahun 2013 ini melakukan investasi tanggung jawab sosial perusahaan yang dialokasikan dari laba bersih dan biaya operasional perusahaan. Fokus program tanggung jawab sosial perusahaan mengikuti konsepsi triple bottom line yang terdiri dari 3P yaitu people, planet, dan profit.

Salah satu program tanggung jawab sosial perusahaan Sido Muncul adalah Program Desa Rempah dan Buah. Tujuan program ini adalah mengembangkan komoditas unggulan dan desa wisata, bekerjasama dengan pemprov, pemkot/ pemkab, LSM, swasta, kelompok tani/ petani, dan aparat terkait. Sido Muncul juga telah memperoleh banyak penghargaan dan sertifikasi bidang tanggung jawab sosial perusahaan dan lingkungan hidup, di antaranya: program PROPER dari Kementerian Lingkungan Hidup dan Kehutanan (KLHK), Green Award dari La Tofie School of CSR, Nusantara CSR Award dari La Tofie School of CSR, dan Ernst and Young Entrepreneur of The Year 2016 Kategori Special Award for CSR.

Ide Desa Rempah dan Buah berasal dari Direksi Sido Muncul, di mana Desa Rempah dikembangkan pada tahun 2014, dan Desa Buah pada tahun 2016. Tujuan mengembangkan Desa Wistata Rempah dan Buah adalah untuk memberdayakan masyarakat sekitar dengan cara budidaya 
tanaman obat dan tanaman buah. Tanaman obat tersebut dapat disuplai sebagai bahan baku jamu ke Sido Muncul dan petani mendapatkan imbal hasil. Tanaman buah untuk pemberdayaan petani agar memperoleh pendapatan tambahan. Ada dua desa yang menjadi binaan Sido Muncul, yaitu Desa Bergas Kidul dan Desa Diwak. Desa Bergas Kidul yang berlokasi di Bandungan memiliki komoditas alpukat wina, yaitu jenis alpukat lokal, dan juga melon, serta wisata embung dan batik. Desa Diwak yang berlokasi di belakang pabrik Sido Muncul memiliki komoditas durian unggulan, yaitu durian pelangi, durian matahari, dan durian bawor. Di Desa Diwak ada juga wisata pemandian air hangat dan air terjun.

Adapun tujuan penelitian ini adalah untuk mengkaji proses kewirausahaan sosial, dan untuk mengidentifikasi penciptaan nilai bersama melalui Program CSR Sido Muncul Desa Rempah dan Buah. Hasil penelitian ini memberikan kontribusi bagi Sido Muncul, yaitu agar perusahaan dapat membuat langkah-langkah yang strategis guna meningkatkan penciptaan nilai bersama secara berkelanjutan. Manfaat bagi warga binaan di Desa Rempah dan Buah adalah dengan adanya kewirausahaan sosial yang dikembangkan Sido Muncul, diharapkan masyarakat setempat selain mendapatkan kesejahteraan ekonomi, juga sekaligus dapat mengembangkan usaha melalui peluang sosial di sekitarnya.

\section{METODE}

Metode penelitian yang digunakan bersifat kualitatif. Menurut Johnson, Dunlap dan Benoit (2010), metode penelitian kualitatif biasanya digunakan untuk lebih memahami fenomena yang masih sedikit datanya sehingga mendukung penemuan informasi baru. Neale (2016) menambahkan, analisis kualitatif menggunakan data, untuk mengaturnya dan memecahnya, menjadi unit yang dapat dikelola, mensintesisnya, mencari pola, menemukan apa yang penting dan apa yang harus dipelajari, serta memutuskan apa yang akan dikatakan kepada orang lain. Dalam penelitian ini dilakukan pendekatan studi kasus pada Perusahaan Sido Muncul yang memiliki program CSR yaitu Desa Rempah dan Buah. Lokasi penelitian untuk mengembangkan model kewirausahaan sosial berada di Desa Bergas Kidul dan Desa Diwak di Kabupaten Semarang.

Data yang dikumpulkan adalah data primer dan data sekunder. Data primer diperoleh dengan wawancara dan observasi kepada Sido Muncul dan mitra binaan. Wawancara mendalam pada metode penelitian kualitatif dianggap optimal untuk mengumpulkan data tentang praktik dan pengalaman perusahaan sendiri, terutama saat topik sensitif dieksplorasi (Qu \& Dumay, 2011). Wawancara kepada Sido Muncul diwakili oleh Bagian Humas, yang untuk kemudahan pembahasan diberi kode tersendiri, yaitu Ibu Marianingsih, Ibu Mia Maharani Purbaningrum, Pak Bambang Supartoko, dan Ibu Fadhila Rifka Widati. Pertanyaan wawancara adalah tentang CSR Sido Muncul, yaitu program Desa Rempah dan Buah. Wawancara dan observasi kepada mitra binaan program CSR Sido Muncul juga dilakukan. Para mitra tersebut juga diberi kode untuk memudahkan pembahasan. Perwakilan dari program Desa Rempah dan Buah di Desa Bergas Kidul, di antaranya: Ibu Anna sebagai Staf Teknis Perpustakaan Bergas Kidul dan Bagian Pokja 3 untuk Pangan, Sandang, Perum; Bapak Anas Maulana sebagai SekDes di Bergas Kidul; Ibu Mariyanti sebagai Ketua Tim Penggerak PKK di Bergas Kidul. Adapun perwakilan mitra binaan dari Desa Diwak, di antaranya: Bapak Agus Sukoco, sebagai Kasi Pemerintahan Desa Diwak dan Bapak Purwanto, sebagai Kasi Kesra Desa Diwak. Data sekunder diperoleh dari laporan tahunan Sido Muncul dari tahun 2013-2018. Keabsahan data diuji dengan metode triangulasi, yaitu penggunaan beberapa metode atau sumber data dalam penelitian kualitatif untuk dikembangkan pemahaman yang komprehensif tentang fenomena (Carter et al, 2014). Keandalan wawancara lebih tinggi untuk data yang objektif daripada data yang subjektif (Seidler, 1974). Penelitian ini menggunakan pendekatan grounded theory karena prosedur 
kerjanya yang dirancang secara cermat sehingga memenuhi kriteria metode ilmiah (Glaser \& Strauss, 2017). Tujuan dari grounded theory approach adalah teoritisasi data yang berorientasi tindakan atau interaksi, karena sesuai untuk penelitian terhadap perilaku (Creswell, 2008).

\section{HASIL DAN PEMBAHASAN}

Pembahasan disesuaikan dengan tujuan penelitian, yaitu untuk mengkaji proses pengembangan kewirausahaan sosial dan untuk mengidentifikasi penciptaan nilai bersama melalui Program CSR Sido Muncul Desa Rempah dan Buah.

\section{Proses Pengembangan Kewirausahaan Sosial untuk Program Desa Rempah dan Buah}

Proses yang dilakukan dalam pengembangan kewirausahaan sosial dilakukan melalui tiga tahapan yaitu tahap input berupa identifikasi masalah sosial, tahap proses berupa alokasi sumber daya, kolaborasi dan kemitraan, serta adaptasi produk dan proses, dan yang terakhir, tahap output, yaitu inovasi sosial atau model bisnis baru.

\section{Tahap Input: Identifikasi Masalah}

Sebelum menjalankan program pengembangan kewirausahaan sosial melalui CSR, Sido Muncul terlebih dahulu mengidentifikasi masalah yang terdapat di Desa Rempah dan Buah. Pada Desa Bergas Kidul dan Desa Diwak, masalah sosial yang dihadapi terkait dengan kualitas sumber daya manusia. Masyarakat Desa Bergas Kidul masih memerlukan bantuan branding dan marketing untuk pengembangan produk olahan, sedangkan masyarakat Desa Diwak memerlukan pelatihan untuk memaksimalkan produktivitas petani.

Tahap Proses: Alokasi Sumber Daya, Kolaborasi dan Kemitraan, serta Adaptasi Produk dan Proses

Sido Muncul mengalokasikan sumber daya untuk kelancaran program CSR di Desa Rempah dan Buah. Sumber daya yang diberikan adalah input pertanian, di antaranya: bibit, pupuk, air, dan saranaprasarana, seperti peralatan, mesin, dan infrastrukur. Untuk itu, Sido Muncul melakukan koordinasi dengan pihak ketiga seperti pemerintah, akademisi, NGO, atau konsultan untuk melakukan kegiatan penyuluhan dan pendampingan. Bibit yang diberikan di Desa Bergas Kidul adalah bibit alpukat, sedangkan bibit yang diberikan di Desa Diwak adalah bibit durian. Untuk mempermudah proses pembinaan, maka para petani dibagi dalam kelompok-kelompok kecil, kemudian dilakukan pendampingan selama proses produksi dan pelatihan pascapanen.

Kolaborasi dan kemitraan yang dilakukan Sido Muncul adalah bekerjasama dengan pihak-pihak terkait, di antaranya dengan bagian internal dan eksternal perusahaan Sido Muncul. Pihak internal perusahaan adalah sebagai berikut: direksi, humas, tim promosi (charity), tim teknis (budidaya tanaman). Pihak eksternal perusahaan, di antaranya adalah: pemerintah desa (kepala desa, sie kesejahteraan masyarakat), masyarakat sasaran dari berbagai profesi, konsultan ahli dalam bidang buah dari asosiasi petani alpukat dan durian, dinas pertanian untuk pembinaan pertanian untuk pendataan, dinas pariwisata, dinas pekerjaan umum, dan BBWS (Badan Besar Wilayah Sungai) Pemali Juana.

Adaptasi produk dan proses dilakukan Sido Muncul sebagai upaya perbaikan dari proses pengembangan kewirausahaan sosial dalam program CSR Desa Rempah dan Buah. Adapun adaptasi produk yang terjadi adalah tanaman obat dan tanaman buah sudah menampakkan hasil. Beberapa produk olahan Desa Rempah dan Buah dijual di mini market Sido Muncul. Pengunjung juga menikmati wisata buah alpukat dan melon, embung, batik, dan pentas seni budaya di Desa Bergas Kidul dan wisata buah durian, pemandian air panas, dan air terjun di Desa Diwak. Hal yang menjadi evaluasi di Desa Diwak adalah terkait tentang adaptasi proses, dimana bibit durian yang diberikan kepada masyarakat, tidak semua menampakkan hasil. Oleh karena 
itu ke depan, perlu penyeleksian siapa saja yang memiliki komitmen dan kemampuan dalam budidaya tanaman buah, dan pendampingan yang lebih intensif, sehingga tingkat keberhasilan meningkat.

\section{Tahap Output: Inovasi Sosial (Model Bisnis Baru)}

Sido Muncul menggerakkan Desa ProKlim yaitu Kampung Iklim di Desa Bergas Kidul untuk mengatasi pencemaran udara dengan penanaman apotik hidup di pekarangan rumah warga. Selain itu, di sana juga pengunjung berdatangan untuk menikmati wisata buah alpukat dan melon, embung, batik, dan pentas seni budaya, sehingga warga binaan memiliki tingkat kesejahteraan yang lebih baik. Bibit tanaman alpukat yang diberikan Sido Muncul telah menghasilkan buah dan warga mendapatkan pembinaan untuk membuat produk dengan bahan dasar alpukat, seperti: brownis, biskuit, es krim, dan keripik daun alpukat, di mana salah satu lokasi distribusi produk adalah di mini market Sido Muncul. Di Desa Diwak, Sido Muncul mengembangkan potensi kepariwisataan, yaitu pemandian air panas, perkebunan durian, dan air terjun pada lahan seluas 65,5 hektar, yang berimplikasi pada kenaikan pendapatan masyarakat.

\section{Penciptaan Nilai Bersama melalui Program Desa Rempah dan Buah}

Penciptaan nilai bersama yang muncul dari program Desa Rempah dan Buah diklasifikasikan atas dua bagian, yaitu nilai bagi Sido Muncul sebagai pihak yang memprakarsai program CSR, atau yang disebut sebagai kinerja organisasi, dan nilai bagi masyarakat Desa Bergas Kidul dan Desa Diwak sebagai pihak yang menerima program CSR, atau yang disebut sebagai kinerja sosial. Selanjutnya, masing-masing bentuk penciptaan nilai bersama dijelaskan di bawah ini.

\section{Kinerja Organisasi}

Hasil penelitian ini menunjukkan bahwa kinerja organisasi dapat dilihat dari dukungan manajemen, komitmen karyawan, reputasi perusahaan, dan keuangan organisasi. Penjabaran masing-masing penilaian kinerja organisasi dielaborasi sebagai berikut.

\section{Dukungan Manajemen}

Sido Muncul mengalokasikan sumber daya untuk kelancaran program CSR Desa Rempah dan Buah. Sumber daya yang diberikan adalah input dan sarana pertanian, seperti bibit, pupuk, air, dan sarana pertanian, seperti peralatan, mesin, dan infrastrukur. Sido Muncul juga mengajak kerjasama dengan pihak ketiga seperti pemerintah, akademisi, NGO, dan konsultan untuk kegiatan penyuluhan dan pendampingan. Bibit yang diberikan di Desa Bergas Kidul adalah bibit alpukat, sedangkan bibit yang diberikan di Desa Diwak adalah bibit durian. Untuk mempermudah proses pembinaan, maka para petani dibagi dalam kelompokkelompok kecil, kemudian dilakukan pendampingan dan pelatihan pasca panen bekerjasama dengan Penyuluh-penyuluh Lapangan (PPL). Sido Muncul memiliki program budgeting yang bernama CAPEX OPEX, di mana dalam program tersebut sudah dialokasikan dana untuk kegiatan CSR.

\section{Komitmen Karyawan}

Karyawan Sido Muncul mendapat fasilitas dari HRD untuk mengikuti sido academic, yaitu sosialisasi kegiatan CSR Sido Muncul yaitu memberikan bantuan kepada kelompok-kelompok rentan, komunitas di seputar pabrik, kemitraan dengan petani, dan pengelolaan lingkungan hidup. Salah satu program CSR yang disosialisasikan adalah Desa Rempah dan Buah yang bermitra dengan masyarakat di sekitar perusahaan. Selain itu, Sido Muncul juga membuka stan company credibility untuk kegiatan pameran CSR Sido Muncul. Hal ini membuat karyawan bangga dengan Sido Muncul karena perusahaan tempat mereka bekerja peduli terhadap masalah-masalah sosial dan lingkungan di sekitarnya. Mereka mengambil pengalaman tersebut dan mendukung kegiatan CSR di lapangan dengan sukacita dan keramahan, melalui pertemuan- 
pertemuan dengan perangkat desa, para pemuka masyarakat, Community Development Officer (CDO), Person in Charge (PIC) dari Program Desa Rempah dan Buah. Walaupun juga ada benturan di lapangan karena latar belakang yang berbeda dengan warga binaan, namun tim CSR Sido Muncul tetap memberikan penyuluhan dan pendampingan kepada masyarakat agar lebih sejahtera melalui koordinasi dan kolaborasi yang fleksibel dan intensif.

\section{Reputasi Perusahaan}

CSR Sido Muncul ada yang erat kaitannya dengan proses bisnis Sido Muncul, seperti budidaya tanaman obat hingga menjamin harga dan pasar, namun juga ada yang sama sekali tidak berhubungan, seperti membuat kerajinan, makanan, dan pariwisata. Namun, perusahaan tetap menjalankan CSR dengan melakukan kegiatan-kegiatan sosial, agar tercipta hubungan yang saling menguntungkan antara Sido Muncul dengan warga binaan. Program CSR Sido Muncul dapat mempengaruhi kegiatan promosi (branding), sehingga masyarakat menjadi mengenal Sido Muncul, membangun reputasi positif tentang Sido Muncul dan kemudian berdampak pada pembelian. Reputasi Sido Muncul terhadap pemberdayaan masyarakat melalui program CSR dapat dilihat melalui penghargaan yang diterima, di antaranya: penghargaan PROPER (Program Penilaian Peringkat Kinerja Perusahaan Dalam Pengelolaan Lingkungan) dari Kementerian Lingkungan Hidup dan Kehutanan, Green Award dari La Tofie School of CSR, Nusantara CSR Award 2016 dari La Tofie School of CSR, dan penghargaan Ernst and Young Entrepreneur of The Year 2016 kategori Special Award for Corporate Social Responsibility.

\section{Keuangan Organisasi}

Pimpinan Sido Muncul meyakini bahwa dengan adanya program CSR, perusahaan akan tetap maju karena bisa melayani masyarakat yang membutuhkan dengan alokasi sumber daya, kolaborasi dan kemitraan, serta inovasi sosial yang dapat dipertanggungjawabkan. Penjualan produkproduk Sido Muncul terus mengalami peningkatan walaupun sebagian pendanaan dialokasikan untuk kepentingan CSR. Banyak investor yang menanamkan dananya di Sido Muncul karena perusahaan memiliki kepedulian kepada pemberdayaan masyarakat. Reputasi Sido Muncul yang positif juga membuat pelanggan memilih mengkonsumsi produk-produknya, sehingga tercipta pembelian berulang yang menaikkan laba perusahaan.

\section{Kinerja Sosial}

Penelitian ini menghasilkan temuan bahwa kinerja sosial dapat dilihat dari peran pengusaha sosial, hubungan yang harmonis antara pemegang saham dengan pemangku kepentingan, inovasi sosial, dan kemandirian komunitas. Penjabaran masing-masing penilaian kinerja sosial dapat dilihat berikut ini.

\section{Peran Pengusaha Sosial}

Program CSR Desa Rempah dan Buah dilakukan melalui kolaborasi dengan para pemangku kepentingan, di antaranya: perangkat desa dan pengusaha sosial yang ada di lingkungan setempat. Sido Muncul mengadakan Focus Group Discussion (FGD) dengan mereka untuk memetakan apa yang menjadi masalah pada target CSR, kemudian mempersiapkan sumber daya yang diperlukan untuk penyelesaiannya. Kemudian, Sido Muncul memberdayakan potensi dan peluang sosial di Desa Bergas Kidul dan Desa Diwak dengan dibantu para pengusaha sosial (local hero) di wilayah tersebut. Para pengusaha sosial itu lebih memahami pengetahuan, keterampilan, dan adat istiadat masyarakat setempat, sehingga lebih mudah dalam berinteraksi dengan warga binaan. Masukan dan peran dari pengusaha sosial dapat memberikan kontribusi untuk menciptakan desa wisata yang memiliki kearifan lokal dan menggali komoditas unggulan yang bisa dibudidayakan untuk kesejahteraan masyarakat. 
Hubungan yang Harmonis antara Pemegang Saham dan Pemangku Kepentingan

Program CSR Sido Muncul dilaporkan secara rutin melalui laporan tahunan kepada para pemegang saham. Para investor memperhatikan program CSR yang memberikan memiliki dampak keberlanjutan seperti peningkatan ekonomi dan pengelolaan lingkungan, sebagai tolok ukur dalam pengambilan keputusan investasi. Kegiatan CSR Sido Muncul dilakukan dengan sistem yang terintegrasi dari hulu sampai hilir, bekerjasama dengan petani, UMKM, koperasi tani, perguruan tinggi, lembaga riset, pemerintah, lembaga bisnis, dan NGO untuk kolaborasi dan kemitraan. Dalam rangka pengadaan bahan baku, Sido Muncul melakukan penelitian tanaman obat dengan eksplorasi alam dan uji laboratorium bekerjasama dengan para akademisi, penyuluhan dan pendampingan dengan petani binaan agar menghasilkan komoditas unggulan yang dapat dipergunakan sebagai bahan baku jamu Sido Muncul. Untuk penjualan produk-produk jamu, Sido Muncul bermitra dengan distributor, agen, dan ribuan outlet, bahkan pedagang asongan untuk penguatan UMKM. Sido Muncul juga bekerjasama dengan perbankan untuk menjadi penjamin kredit bagi petani agar mereka bisa mandiri dan berkelanjutan.

\section{Inovasi Sosial}

Program Desa Buah dan Rempah di Desa Bergas Kidul dan Desa Diwak diawali dengan pemberian bantuan bibit, pupuk, dan sarana pertanian oleh Sido Muncul. Sido Muncul mengembangkan Desa Wisata dengan membantu pembuatan embung yaitu kolam penampungan air untuk irigasi, alam, batik di Desa Bergas Kidul. Jenis buah yang dibudidayakan petani adalah durian bawor dan durian matahari untuk Desa Diwak, sedangkan di Desa Bergas Kidul adalah buah alpukat wina. Sido Muncul menghadirkan seorang ahli tanaman buah dari IPB Bogor untuk pembinaan. Di Desa Diwak, ada juga tanaman semusim seperti ketela cilembu, pare, dan tanaman obat lainnya, yang dibudidayakan dan diolah menjadi produk tani, di sela-sela menunggu panen buah durian. Sido Muncul akan membeli hasil tani mereka untuk kepentingan produksi jamu. Perusahaan juga memberikan fasilitas mini market Sido Muncul sebagai salah satu saluran distribusi petani, sehingga berdampak kepada peningkatan ekonomi rumah tangga warga binaan. Selain itu, di Desa Diwak terdapat wisata pemandian air panas dan air terjun, yang menjadi kawasan wisata bernilai kearifan lokal. Sido Muncul melakukan perbaikan infrastruktur untuk tempat pemandian air panas, seperti perbaikan atap peneduh dan talut sungai, agar masyarakat mendapat penghasilan tambahan dari destinasi wisata tersebut.

\section{Kemandirian Komunitas}

Program CSR Desa Rempah dan Buah bertujuan untuk menciptakan kemandirian dan kontinuitas terhadap mitra CSR. Untuk itu, Sido Muncul mengadakan pelatihan dan pendampingan. Pelatihan yang sudah dilakukan di antaranya: memproduksi handicraft, makanan, dan hasil tani. Sido Muncul juga memberikan bantuan bibit, alat kerja, dan mesin, sebagai upaya kepeloporan perusahaan dalam meningkatkan kesejahteraan masyarakat. Selain itu, Sido Muncul telah memberikan pendampingan berupa penyuluhan dan upaya membantu memasarkan produk-produk yang dihasilkan kelompok tani dengan cara mengirimkan tenaga ahli, membeli hasil tani, dan menyediakan mini market Sido Tetulung untuk menampung produk olahan petani.

\section{Pembahasan}

Kewirausahaan sosial adalah suatu proses menciptakan nilai sosial dengan menggabungkan sumber daya dengan cara baru, di mana kombinasi sumber daya ini dapat mengeksplorasi dan mengeksploitasi peluang serta merangsang perubahan sosial (Mair \& Mart1, 2006; Yunus, Moingeon, \& Lehmann-Ortega, 2010). Tanggung jawab sosial perusahaan dan kewirausahaan sosial adalah konsep saling melengkapi untuk membangun sistem sosial yang sehat dan 
bermartabat (Niño, 2015). Kewirausahaan sosial sebagai corporate social responsibility adalah tanggapan terhadap tuntutan lingkungan, yaitu sebagai inisiatif bisnis yang terkait kebutuhan masyarakat. Kewirausahaan sosial berfokus pada tindakan yang timbul dari organisasi dan manajemen di mana orang-orang, modal, dan kesempatan terlibat dalam penciptaan nilai. Jika kewirausahaan sosial dikaitkan dengan corporate social responsibility maka nilai sosial itu harus selaras dengan nilai organisasi (Austin, Stevenson, \& Wei-Skillern, 2012).

Beberapa penelitian terdahulu tentang proses pengembangan kewirausahaan sosial dalam CSR telah dilakukan oleh Tasavori, Ghauri, dan Zaefarian (2016), Agrawal dan Sahasranamam (2016), serta Nikolov dan Westergren (2017). Tasavori, Ghauri, dan Zaefarian (2016) melakukannya dengan beberapa tahapan, di antaranya: identifikasi masalah sosial sebagai peluang pasar, pengembangan dan adaptasi produk, dan pengembangan dan adaptasi proses pemasaran. Lain lagi dengan Agrawal dan Sahasranamam (2016), proses pengembangan kewirausahaan sosial melalui CSR dilakukan dengan cara sebagai berikut: alokasi dan komitmen sumber daya, melakukan inovasi sosial dan penciptaan model bisnis baru, serta mengembangkan kolaborasi dengan LSM, wirausaha lokal, dan pemerintah. Adapun Nikolov dan Westergren (2017), mengembangkan kewirausahaan sosial dengan terlebih dahulu mengalokasikan sumber daya yang diperlukan, kemudian membentuk kemitraan, baik dengan organisasi sektor sosial maupun lembaga bisnis, serta mengembangkan dan mengevaluasi produk dan pemasaran.

Penelitian ini menemukan tiga hal mendasar dalam proses pengembangan kewirausahaan sosial dalam program CSR Sido Muncul Desa Rempah dan Buah, di antaranya adalah adanya masalah sosial (Certo \& Miller, 2008; Yunus, Moingeon, \& Lehmann-Ortega, 2010), alokasi sumber daya yang digunakan (Sagawa \& Segal, 2000; Petrick \& Quinn, 2000), dan inovasi sosial (Ziegler, 2010; Choi \& Majumdar, 2015).
Untuk itu dibutuhkan kolaborasi dan kemitraan, baik dengan LSM, wirausaha lokal, lembaga bisnis, maupun pemerintah (Nikolov \& Westergren, 2017), sehingga terjadi adaptasi produk dan proses (Tasavori, Ghauri, \& Zaefarian, 2016), yang menghasilkan model bisnis baru (Agrawal \& Sahasranamam, 2016). Adapun proses pengembangan kewirausahaan sosial dalam program CSR Sido Muncul Desa Rempah dan Buah, dapat dilihat pada Gambar 1 berikut ini.

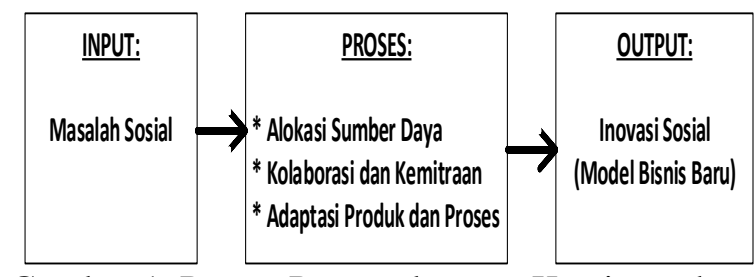

Gambar 1. Proses Pengembangan Kewirausahaan Sosial dalam Program CSR

Hasil dari proses pengembangan kewirausahaan sosial dalam program CSR Sido Muncul Desa Rempah dan Buah adalah penciptaan nilai bersama, yang mana terbagi menjadi dua bagian yaitu kinerja organisasi (Gorondutse \& Hilman, 2017) dan kinerja sosial (Ogundele, Akingbade, \& Akinlabi, 2012). Porter dan Kramer (2011) serta Garriga dan Mele (2017) menambahkan bahwa gagasan CSR akan menghasilkan nilai perusahaan, baik untuk kepentingan ekonomi maupun sosial, sehingga kewajiban bisnis untuk menjalankan tujuan dan nilai masyarakat.

Kinerja organisasi berhubungan dengan dukungan manajemen dalam kegiatan bisnis dan praktik, sehingga menghasilkan transparansi organisasi dan pengungkapan kepada para pemangku kepentingan di seluruh rantai nilai (Du, Bhattacharya, \& Sen, 2010). Peterson (2004) dan Branco dan Rodrigues (2006) mengungkapkan tindakan tanggung jawab sosial perusahaan cenderung memberikan dampak positif pada komitmen karyawan. Karyawan menjadi lebih berdedikasi untuk memastikan kualitas pengalaman di tempat kerja, dan terlatih menangani masalah sosial, seperti perlindungan lingkungan atau kesejahteraan masyarakat (Maignan, Ferrell, \& Hult, 1997). 
Branco dan Rodrigues (2006) menambahkan ketika perusahaan mampu berkomunikasi secara efektif dengan berbagai pemangku kepentingan sesuai dengan kriteria sosial dan etika, maka mereka dapat membangun reputasi perusahaan yang positif, yang sangat penting kontribusinya bagi keunggulan kompetitif perusahaan (Roberts, 2000). Organisasi yang mengeluarkan biaya tinggi untuk CSR akan mengurangi biaya ekuitas pemilik dan menarik lebih banyak investor, sehingga kinerja keuangan mereka menjadi unggul (Dhaliwal, Zhen, Tsang, \& George, 2014). Menurut Gorondutse \& Hilman (2017), tanggung jawab sosial perusahaan mempengaruhi keuangan organisasi dalam berbagai cara, di antaranya perusahaan akan tumbuh dengan cepat, mendapatkan pendapatan maksimum di pasar, dan akan mampu mengalahkan pesaing.

Program CSR yang menciptakan kewirausahaan sosial dapat memunculkan kinerja sosial, di antaranya perilaku berbudi pekerti dari wirausaha sosial yang terkait dengan dimensi kebajikan sebagai operasionalisasi dari misi sosial (Morgan, 1988). Wirausaha sosial mampu menjaga keseimbangan antara kepentingan sosial dan bisnis (Bhattacharya, Sen, \& Korschun, 2008), sehingga tercipta hubungan yang harmonis antara pemegang saham dan pemangku kepentingan (Orlitzky, Schmidt, Rynes, \& Rynes, 2000; Lins, Servaes, \& Tamayo, 2017). Menurut Dees (2008), inovasi sosial dengan kombinasi penggunaan sumber daya dalam lingkungan yang dinamis dan kompetitif, dapat dihasilkan dari program CSR berbasis kewirausahaan sosial. Perusahaan berkontribusi untuk menciptakan kemandirian komunitas dengan kapasitas dan integritas yang dimilikinya (Ogundele, Akingbade, \& Akinlabi, 2012), sehingga memiliki kesatuan tujuan dan tindakan dalam menghadapi kompleksitas (Petrick \& Quinn, 2000).

Kinerja organisasi dan kinerja sosial memiliki hubungan timbal balik yang akan menghasilkan pertumbuhan berkelanjutan (Mair \& Mart1, 2006), baik bagi Sido Muncul maupun warga binaan untuk Program CSR
Desa Rempah dan Buah. Adapun kerangka kerja penciptaan nilai bersama program CSR Sido Muncul Desa Rempah dan Buah terdapat pada Gambar 2 berikut ini.

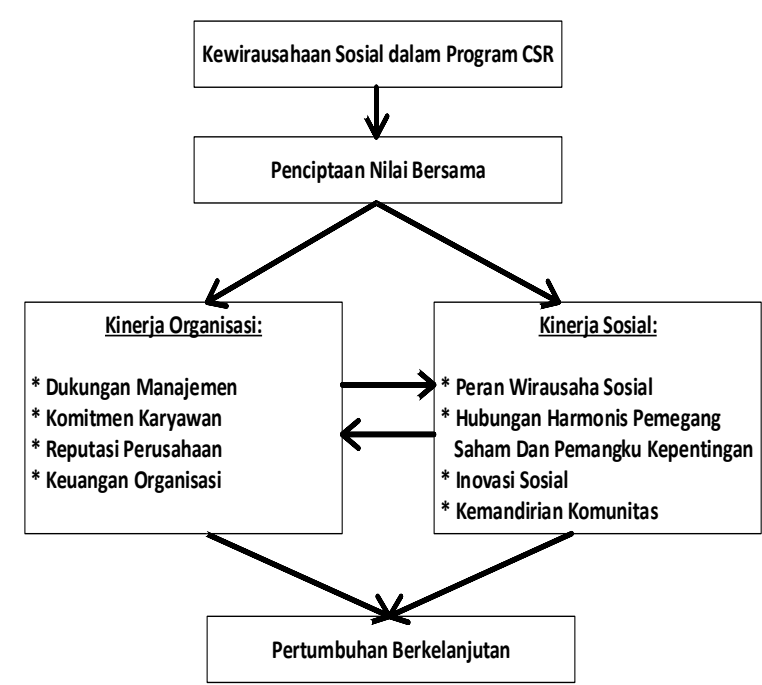

Gambar 2. Kerangka Kerja Penciptaan Nilai Bersama

\section{Kesimpulan}

Proses yang dilakukan dalam pengembangan kewirausahaan sosial dalam program CSR Desa Rempah dan Buah terdiri dari tahap input, proses, dan output. Tahap input adalah identifikasi masalah sosial yang terjadi di Desa Bergas Kidul dan Desa Diwak sebagai ikon Desa Wisata Rempah dan Buah, yaitu masalah kualitas sumber daya manusia. Tahap proses adalah alokasi sumber daya berupa bibit, pupuk, air, dan sarana-prasarana, seperti peralatan, mesin, dan infrastrukur, kemudian kolaborasi dan kemitraan, serta adaptasi produk dan proses. Tahap output adalah inovasi sosial atau model bisnis baru. Sido Muncul menggerakkan Desa ProKlim, destinasi desa wisata yang kaya tanaman rempah dan buah, pembuatan produk olahan dari bahan baku rempah dan buah, wisata embung, pameran batik, pemandian air panas dan air terjun, serta pameran seni budaya sebagai wujud kearifan lokal, yang berimplikasi pada kenaikan pendapatan masyarakat. Adapun penciptaan nilai sosial yang dihasilkan dari proses pengembangan kewirausahaan sosial melalui program CSR adalah kinerja organisasi dan kinerja sosial. Kinerja organisasi dinilai dari dukungan 
manajemen, komitmen karyawan, reputasi perusahaan, dan keuangan organisasi. Kinerja sosial dinilai dari peran wirausaha sosial, hubungan yang harmonis antara pemegang saham dan pemangku kepentingan, inovasi sosial, dan kemandirian komunitas.

Penelitan ini menghasilkan dua temuan (novelty) yaitu kerangka kerja proses pengembangan kewirausahaan sosial dan kerangka kerja penciptaan nilai bersama, di mana keduanya dalam konteks tanggung jawab sosial perusahaan untuk pertumbuhan berkelanjutan.

Desa Rempah dan Buah sebagai program CSR Sido Muncul telah menghasilkan inovasi sosial berupa kawasan Desa Wisata Rempah dan Buah dengan komoditas unggulan alpukat wina, durian pelangi, durian matahari, durian bawor, budidaya tanaman obat, wisata pemandian air hangat dan air terjun, pengembangan batik, serta aneka produk olahan, sehingga menghasilkan kemandirian komunitas. Namun demikian, perlu dikaji lebih dalam tentang hubungan antara CSR dan sustainable development, sehingga penelitian ke depan, dapat diteliti tentang "Strategi Pertumbuhan Berkelanjutan Melalui Penguatan Inkubator Bisnis dan Inovasi Teknologi Berbasis Kearifan Lokal (Studi Kasus pada Program CSR Sido Muncul)".

\section{DAFTAR PUSTAKA}

Agrawal, A., \& Sahasranamam, S. (2016). Corporate social entrepreneurship in India. South Asian Journal of Global Business Research, 5(2), 214-233. https://doi.org/10.1108/SAJGBR-122014-0098

Austin, J., Stevenson, H., \& Wei-Skillern, J. (2012). Social and commercial entrepreneurship: same, different, or both? Revista de Administração, 47(3), 370-384.

https://doi.org/10.5700/rausp1055

Bhattacharya, C., Sen, S., \& Korschun, D. (2008). Using corporate social responsibility to win the war for talent.
MIT Sloan Management Review, 49(2), 37-44. https://doi.org/10.1007/s10551008-9812-2

Branco, M. C., \& Rodrigues, L. L. (2006). Corporate social responsibility and resource-based perspectives. Journal of Business Ethics. https://doi.org/10.1007/s10551-0069071-z

Burrell, L., Hewlett, S. A., Luce, C. B., \& Frohman, D. (2006). K g Str gy out of His Mouth. North, 84(December), 7892.

https://doi.org/10.1287/mnsc. 1090.1070

Carter, N., Bryant-Lukosius, D., DiCenso, A., Blythe, J., \& Neville, A. J. (2014). The Use of Triangulation in Qualitative Research. Oncology Nursing Forum, 41(5), 545-547. https://doi.org/10.1188/14.ONF.545547

Certo, S. T., \& Miller, T. (2008). Social entrepreneurship: Key issues and concepts. Business Horizons. https://doi.org/10.1016/j.bushor.2008.02 .009

Choi, N., \& Majumdar, S. (2015). Social innovation: Towards a conceptualisation. In Technology and Innovation for Social Change. https://doi.org/10.1007/978-81-3222071-8_2

Creswell, J. W. (2008). Research Design: Qualitative, Quantitative, and Mixed Methods Approaches. Thousand Oaks, CA: Sage Publications.

Dees, J. G. (2008). Philanthropy and Enterprise: Harnessing the Power of Business and Social Entrepreneurship for Development. Innovations: Technology, Governance, Globalization, 3(3), 119-132. https://doi.org/10.1162/itgg.2008.3.3.11 9

Dhaliwal, D., Zhen, O., Tsang, A., \& George, Y. (2014). J . Account . Public Policy Corporate social responsibility disclosure and the cost of equity capital : The roles of stakeholder orientation and financial transparency. Journal of 
Accounting And Public Policy. https://doi.org/10.1016/j.jaccpubpol.201 4.04.006

Du, S., Bhattacharya, C. B., \& Sen, S. (2010). Maximizing business returns to corporate social responsibility (CSR): The role of CSR communication. International Journal of Management Reviews, 12(1), 8-19. https://doi.org/10.1111/j.14682370.2009.00276.x

Falck, O., \& Heblich, S. (2007). Corporate social responsibility: Doing well by doing good. Business Horizons, 50(3), 247-254.

https://doi.org/10.1016/j.bushor.2006.12 .002

Garriga, E., \& Mele, D. (2017). Corporate social responsibility theories: Mapping the territory. Corporate Social Responsibility, 107-127.

Glaser, B. G. \& Strauss, A. L. (2017). The Discovery of Grounded Theory: Strategies for Qualitative Research. New York: Routledge.

Gorondutse, A. H., \& Hilman, H. (2017). Effect of Business Social Responsibility ( BSR ) on Performance of SMEs : Data Screening and Preliminary Analysis, 10(8).

https://doi.org/10.5539/ass.v10n8p103

Harris, H. (2016). Hemingway, C.A. (2014). Corporate Social Entrepreneurship: Integrity Within. Cambridge, UK: Cambridge University Press. In $\mathrm{M}$. Schwartz, H. Harris, \& D. R. Comer (Eds.), Research in Ethical Issues in Organizations (Vol. 16, pp. 233-239). Emerald Group Publishing Limited. Retrieved from http://www.emeraldinsight.com/doi/10. 1108/S1529-209620160000016015

Idowu, S. O., Louche, C., \& Filho, W. L. (2013). Innovative corporate social responsibility: An introduction. Innovative CSR: From Risk Management to Value Creation, 44(0), 1-10. https://doi.org/10.9774/gleaf.9781-907643-26-2_2

Ireland, R. D., Covin, J. G., \& Kuratko, D. F.
(2009). Conceptualizing corporate entrepreneurship strategy. Entrepreneurship: Theory and Practice. https://doi.org/10.1111/j.15406520.2008.00279.x

Johnson, B. D., Dunlap, E., \& Benoit, E. (2010). Organizing "Mountains of Words" for Data Analysis, both Qualitative and Quantitative. Substance Use \& Misuse, 45(5), 648-670. https://doi.org/10.3109/1082608100359 4757

Kozubek, R. (2015). The Link Between Innovation And Csr. Short Look On A Bi-Directional System Of InnovationDriven Csr And Csr-Driven Innovation, 11.

Kuratko, D. F., Ireland, R. D., Covin, J. G., \& Hornsby, J. S. (2005). E T P A Model of Middle- \& Level Managers' Entrepreneurial Behavior. Entrepreneurship Theory And Practice, 18.

Lantos, G. P. (2001). The Boundaries of Strategic Corporate Social Responsibility," The Journal of Consumer Marketing, 18(7), 595-630.

Lins, K. V, Servaes, H., \& Tamayo, A. N. E. (2017). Social Capital , Trust, and Firm Performance: The Value of Corporate Social Responsibility, LXXII(4). https://doi.org/10.1111/jofi.12505

Lodge, G., \& Wilson, C. (2006). Multinational Corporations and Global Poverty Reduction. Challenge, 49(3), 17-25. https://doi.org/10.2753/cha05775132490302

López, M. V., Garcia, A., \& Rodriguez, L. (2007). Sustainable development and corporate performance: A study based on the Dow Jones sustainability index. Journal of Business Ethics, 75(3), 285300 . https://doi.org/10.1007/s10551006-9253-8

Maignan, I., Ferrell, O. C., \& Hult, G. T. M. (1997). Corporate Citizenship : Cultural Antecedents and Business Benefits, (2).

Mair, J., \& Mart1, I. (2006). Social entrepreneurship research: A source of explanation, prediction, and delight, 41, 
$36-44$.

https://doi.org/10.1016/j.jwb.2005.09.0 02

Marquez Ezequiel, P. R., Berger, G., Marquez, P., Reficco, E., Berger, G., Marquez Ezequiel , P. R., \& Berger, G. (2010). Socially Inclusive Business Engaging the Poor through Market Initiatives in Iberoamerica $A$ Collaborative Research Project of the Editorial Committee. Initiatives.

Martin, R. L., \& Osberg, S. (2007). Social Entrepreneurship: The Case for Definition. Retrieved from www.ssireview.org

Mcwilliams, A., \& Siegel, D. (2001). Corporate Social Responsibility: A Theory Of The Firm Perspective. (® Academy ol Management Review (Vol. 26).

Mitchell, R. K., Agle, B. R., \& Wood, D. J. (1997). Toward a Theory of Stakeholder Identification and Salience: Defining the Principle of Who and What Really Counts Authors ( s ): Ronald K . Mitchell , Bradley R . Agle and Donna J . Wood Source: The Academy of Management Review, Vol. 22, No. 4 ( Oct. The Academy of Management Review, 22(4), 853-886.

https://doi.org/10.5465/AMR.1997.971 1022105

Morgan, G. (1988). Riding The Waves of Change. San Francisco: Jossey-Bass.

Neale, J. (2016). Iterative categorization (IC): A systematic technique for analysing qualitative data. Addiction, 111(6), 1096-1106. https://doi.org/10.1111/add.13314

Nikolov, A., \& Westergren, L. (2017). Corporate Social Entrepreneurship as a new approach to CSR-A Swedish Outlook.

Niño, A. C. S. (2015). Social Entrepreneurship and Corporate Social Responsibility: Differences and Points in Common. Journal of Business, 2(2), 9.

Ogundele,O.J.K., Akingbade, W.A., \& Akinlabi, H.B. (2012). Entrepreneurship Training and Education As Strategic
Tools For Poverty Alleviation in Nigeria. American International Journal of Contemporary Research, 2(1), 148156.

Orlitzky, M., Schmidt, F. L., Rynes, S. L., \& Rynes, S. L. (2000). Corporate Social and Financial Performance: A Metaanalysis, 403-441.

Partzsch, L., \& Ziegler, R. (2011). Social entrepreneurs as change agents: a case study on power and authority in the water sector. International Environmental Agreements: Politics, Law and Economics, 11(1), 63-83. https://doi.org/10.1007/s10784-0119150-1

Perrini, F., \& Vurro, C. (2006). Social Entrepreneurship: Innovation and Social Change Across Theory and Practice. Social Entrepreneurship, 57-85. https://doi.org/10.1057/9780230625655

Peterson, D. K. (2004). of Corporate Citizenship and, 43(3), 296-319. https://doi.org/10.1177/0007650304268 065

Petrick, J. A., \& Quinn, J. F. (2000). The Integrity Capacity Construct and Moral Progress in Business, 3-4.

Porter, M. E., \& Kramer, M. R. (2011). The Big Idea: Creating Shared Value Moving Beyond Trade-Offs The Roots of Shared Value. Fortune, 1-12.

Qu, S. Q., \& Dumay, J. (2011). The qualitative research interview. Qualitative Research in Accounting and Management (Vol. 8). https://doi.org/10.1108/1176609111116 2070

Roberts, P. W. (2000). Fortune's Most Admired, 1-7.

Saatci, E. Y., \& Urper, C. (2013). Corporate Social Responsibility versus Social Business. Journal of Economics, Business and Management, 62-65. https://doi.org/10.7763/JOEBM.2013.V 1.15

Sagawa, S., \& Segal, E. (2000). Common Interest, Common Good: Creating Value Through Business and Social Sector Partnerships. California Management 
Review.

https://doi.org/10.2307/41166035

Salzmann, O., Ionescu-Somers, A. M., \&

Steger, U. (2005). The business case for corporate sustainability: Literature review and research options. European Management Journal, 23(1), 27-36. https://doi.org/10.1016/j.emj.2004.12.0 07

Seidler, J. (1974). On Using Informants: A Technique for Collecting Quantitative Data and Controlling Measurement Error in Organization Analysis. American Sociological Review. https://doi.org/10.2307/2094155

Shane, S., \& Venkataraman, S. (2000). The Promise Of Entrepreneurship As A. Field Of Research. Management Review (Vol. 25).

Sila, I., \& Cek, K. (2017). The impact of environmental, social and governance dimensions of corporate social responsibility: Australian evidence. Procedia Computer Science, 120, 797 804.

https://doi.org/10.1016/j.procs.2017.11. 310

Slater, S. F., \& Narver, J. C. (1995). Market Orientation and the Learning Organization, 63-74.

Spitzeck, H., Boechat, C., \& França Leão, S. (2013). Sustainability as a driver for innovation - towards a model of corporate social entrepreneurship at Odebrecht in Brazil. Corporate Governance: The International Journal of Business in Society, 13(5), 613-625. https://doi.org/10.1108/CG-06-20130080

Tasavori, M., Ghauri, P. N., \& Zaefarian, R. (2016). Entering the base of the pyramid market in India: A corporate social entrepreneurship perspective. International Marketing Review, 33(4), 555-579. https://doi.org/10.1108/IMR03-2014-0085

Vachani, S., \& Smith, N. C. (2008). Socially Responsible Distribution: Distribution Strategies for Reaching the Bottom of the Pyramid. Ssrn, 50(2), 52-84. https://doi.org/10.2139/ssrn.1116630

Wood, M. (2014). the Production of Entrepreneurial Opportunity: a Constructivist Perspective. Strategic Entrepreneurship Journal, 8(6), 45174524. https://doi.org/10.1002/sej

Yunus, M., Moingeon, B., \& LehmannOrtega, L. (2010). Building social business models: Lessons from the grameen experience. Long Range Planning. https://doi.org/10.1016/j.lrp.2009.12.00 5

Zhang, H., \& Zhang, M. (2016). The Corporate Social Entrepreneur: From Concept to Practice. Global Business and Organizational Excellence, 35(2), 50-59. https://doi.org/10.1002/joe.21655

Ziegler, R. (2010). Innovations in Doing and Being: Capability Innovations at the Intersection of Schumpeterian Political Economy and Human Development. Journal of Social Entrepreneurship. https://doi.org/10.1080/19420676.2010. 511818 